University of Windsor

Scholarship at UWindsor

2012

\title{
Development and use of a Restorative Justice Ideology Instrument: Assessing beliefs
}

\author{
Roland Karen \\ University of Windsor \\ Glenn Rideout \\ University of Windsor \\ Geri Salinitri \\ University of Windsor \\ Marc P. Frey \\ University of Windsor
}

Follow this and additional works at: https://scholar.uwindsor.ca/educationpub

Part of the Education Commons

\section{Recommended Citation}

Karen, Roland; Rideout, Glenn; Salinitri, Geri; and Frey, Marc P.. (2012). Development and use of a Restorative Justice Ideology Instrument: Assessing beliefs. Contemporary Justice Review: Issues in Criminal, Social, and Restorative Justice, 15 (4), 435-447.

https://scholar.uwindsor.ca/educationpub/18

This Article is brought to you for free and open access by the Faculty of Education at Scholarship at UWindsor. It has been accepted for inclusion in Education Publications by an authorized administrator of Scholarship at UWindsor. For more information, please contact scholarship@uwindsor.ca. 
Development and use of a Restorative Justice Ideology Instrument: Assessing beliefs

\author{
Karen Roland* \\ Glenn Rideout \\ Geri Salinitri \\ Marc P. Frey
}

Faculty of Education, University of Windsor, Windsor, Ontario, Canada

*Corresponding Author

roland1@uwindsor.ca

Experiential Learning Specialist

Faculty of Education

University of Windsor

401 Sunset Avenue

Windsor, Ontario, Canada

N9B 3P4

519-253-3000 ext. 4288 


\begin{abstract}
Researchers have noted that restorative justice $(\mathrm{RJ})$ practices in schools seem to improve targeted outcomes (e.g., decreased office visits, increased grades, etc.). It has been acknowledged that a 'grass roots' (beliefs level) buy-in from teachers is necessary for the creation of a school environment that is in line with the ideals of RJ. In the current study, an operational definition for restorative justice ideology was developed and used as the basis for the creation of a Restorative Justice Ideology (RJI) measurement instrument. This is intended to facilitate understandings of the influence that RJ training has on individuals at the beliefs level, and whether the degree to which an individual holds an RJI is associated with the degree to which RJ practices are carried out at the classroom and school level. An exploratory factor analysis was conducted, a three-factor model was selected, and the instrument was tested for reliability and validity. The RJI was then used to investigate whether other individual differences were related to the RJI of teachers. The outcome of this study was the development of a psychometrically sound RJI instrument. Perspective-taking, empathic concern, pupil control ideology, personal distress, and self-efficacy were identified as important characteristics of RJI.
\end{abstract}

Keywords: restorative justice, restorative justice ideology, restorative practice, empathy, pupil control ideology, self-efficacy 


\section{Introduction}

Restorative justice is grounded in the beliefs systems of Indigenous peoples around the world including the aboriginal peoples of North America, the Maori of New Zealand, and the native cultures of Australia, Japan and Africa. Restorative justice advocates (Amstuz \& Mullet, 2005; Braithwaite, 2002; Karp \& Breslin, 2001; Roche 2003, Zehr, 1990) view harm as a violation of peoples' rights and relationships, rather than of rules, laws, or policies. Cormier (2002) defined restorative justice as an approach that focused on repairing the harm caused by offending behaviour while holding the offender accountable for his or her actions. It provided an opportunity for the parties directly affected by such behaviour (victims, offenders, and community) to identify and address their needs that result from the offending behaviour and seek a resolution that affords reparation, healing and reintegration, and prevents future harm. In schools, restorative justice has emerged from Conflict Resolution Education, Character Education, and Emotional Literacy (Amstuz \& Mullet). Lessons learned from these initiatives position practices arising from restorative justice as a means of focusing on the relational and transformative elements of school discipline.

In 2000, the Safe Schools Act (Bill 81), was introduced by the Ontario (Canada) Ministry of Education to "increase respect and responsibility.... and set standards for safe learning and safe teaching in schools" (p.1). Administrators across the province responded to this legislation in a variety of ways. Most emphasized mandatory consequences for student actions (zero tolerance), others explored progressive discipline, and others introduced preventative measures such as anti-bullying and conflict resolution (Safe School Action Team, 2006). From a policy perspective, researchers found that zero tolerance policies are associated with emotional harm, excessive enforcement efforts and increasing delinquency as a response to coercive controls (Karp \& Breslin, 2001; Stinchomb, Bazemore, \& Riestenberg, 2006). Mandatory suspensions 
and expulsion policies have resulted in "reckless and punitive approaches" (Colorosso, 2002, p.184). A study from the Institute of Safe Schools in British Columbia (2005) found that most students perceive consequences for wrongdoers as ineffective, perceive teachers as lacking concern for victims, and perceive bullying and violence as part of the norm. According to Colorosso, zero tolerance and anti-bullying policies equate to "zero-thinking" policies. In response, in 2007, the Ministry amended the Safe Schools Act (Bill 212) and challenged the school boards to assess and improve upon their current disciplinary practices and support students in reaching their potential academically, personally and socially. Ontario's Minister of Education Dombrowsky (2010) asserted that "students need a safe and inclusive learning environment....By making schools safer, we are helping to boost student success" (p.2). As a result of these changes in the Ontario Safe Schools Act (Bill 212), there is considerable interest in restorative justice practices in Ontario School Boards.

Porter (2007) found that an increasing number of schools worldwide adopted restorative practices as a means of dealing with discipline and improving school culture. The restorative approach centers on the relationship students have with their teachers, peers, and school community. According to Fopiano and Haynes (2001), building relationships significantly contributes to students' sense of belonging, social status, self-esteem and connectedness. The International Institute of Restorative Practices indicated that school boards need to embrace restorative justice as a way to think holistically about safe schools, conflict, relationships and community (IIRP, 2010). Watchel and McCold (2001) expanded the relevance of restorative justice to engage educators at the grassroots to apply restorative practices in all aspects of everyday life and teaching. Further, Zehr (1990) argued that for successful restoration with a focus on building and repairing relationships, implementation should focus on people being 
internally guided by moral values. While there is a growing body of research on effectiveness of restorative justice practices, most of this research looks at the changes in retributive response rates. There is a noted absence of research that takes a holistic view of restorative justice ideology. As well, there appears to be a dearth of research that has examined the effectiveness of both restorative practices and their implementation in schools.

In 2009, in response to the ministry's 'Safe Schools' legislation, a pilot study, initiated by a Southwestern Ontario school board, was used to measure the impact of a restorative justice (RJ) intervention in seven schools with regard to three specific aims: reduction in behavioural infractions; creation of a culture of positive relationships; and improved academic achievement (Rideout, Roland, Salinitri, \& Frey, 2010). In this study participants reported a high degree of sensitivity for cultural and equity issues among their students, as well as an improved moral tone within the school. Additionally, it was noted that there was statistical evidence of a reduction in safety (e.g. bullying, fighting, hands-on and 'throwing objects') and insubordination issues (e.g. harassment, language, racial slurs, insubordination, and smoking). Participants articulated improved school climate as a supportive and nurturing school culture that fostered reparation through inclusive practices to ensure that everyone's voice is heard, and that promoted reintegration through building student capacity in terms of healthy relationships based on personal responsibility, accountability and empathy (Rideout, Roland, Salinitri \& Frey). The authors recommended the creation of a school environment that is supportive of an RJ culture be developed at a 'grass roots' level in schools. Following from this, a further study was conducted in 2010-2011 to create an instrument to measure the degree to which educators identified with a personal beliefs orientation that is consistent with the restorative justice principles of healing, cooperation, and restoration. 


\section{Development of a Restorative Justice Ideology Instrument}

In the preceding work of Rideout, Roland, Salinitri, and Frey (2010), it was noted that restorative justice practices resulted in positive outcomes in schools. To better understand the influence that restorative justice training has on the individual, the classroom, and the school, it was concluded that an instrument to measure restorative justice ideology was needed. Therefore, the purpose of the current study was to create an instrument to measure the degree to which educators identified with a personal beliefs orientation that is consistent with the restorative justice principles of healing, co-operation, and restoration.

The purpose of this study was to: (a) develop a construct definition for Restorative Justice Ideology (RJI) based on ideas, attitudes and behaviours that are thought to engender restorative justice; (b) create an RJI measure for teachers based on the definition decided upon in the previous stage of development; (c) determine the factor structure of the measure; (d) assessed the validity of the RJI measure; and (e) investigate relationships between other variables of interest. The design of the study involved two stages. In Stage 1, Phase 1 of the study a construct definition for Restorative Justice Ideology (RJI) was generated, and a Restorative Justice Ideology (RJI) instrument was subsequently developed. Stage 1, Phase 2 of the study involved data collection, an exploratory factor analysis, and a focus group session. Stage 2, Phase 1 involved validation of the measure and use of the measure in predictive models.

A two-stage approach was implemented to first assess the factor structure and reliability of the RJI instrument, and then, in the second stage, the validity and reliability of the RJI instrument was assessed, the framework for a nomological network was established and predictive relationships were investigated. 


\section{Stage 1, Phase 1}

Restorative Justice Ideology construct definition. Foss (1976) suggested that the presence of an ideology is considered vital to a successful social movement (p. 3). Bearing this in mind, a construct definition of an RJ ideology based on a coherent set of beliefs and values congruent with what Zehr (2002) referred to as an 'alternative justice paradigm' was the underpinning for this study. Zehr purported that RJ recognizes a central obligation "to put right the wrongs" ( $p$. 19), and takes into account the needs of the victim (including information, truth-telling, empowerment, and restitution or vindication), the offender (including accountability, personal transformation, re-integration, and in some cases, temporary restraint), and the community (including concerns of victims, sense of community and mutual accountability, and ability to foster conditions that promote healthy communities). This is consistent with Marshall's (1999) contention that RJ incorporates the rights of the victim with the accountability of the offender through the development of a working community (school system), focused on the restoration and reintegration of all of its members. Therefore, for the purposes of this study, it was proposed that an operational definition of an RJ ideology would encompass a sense of competency in terms of 'RJ efficacy', RJ goals and a vision for the future of RJ in schools.

To develop a construct definition of Restorative Justice Ideology an extensive literature review was conducted. The definition of ideology was first explored and considered. Once this definition was determined, it was applied in the development of a Restorative Justice Ideology construct as follows: Restorative Justice Ideology is a deep structure personal beliefs orientation that is consistent with the principles of healing, cooperation, and restoration. It should be noted that this definition underscores the restorative aspect of relationships, and aligns with the belief that restorative justice is both a preventative as well as a reactive approach. 
Initial development of the Restorative Justice Ideology instrument. The process of identifying an inventory of items to measure the RJI construct was begun by compiling a list of tenets that comprise restorative justice, and which have been identified by scholars in the literature. The following 12 tenets were identified as central to the RJI construct definition: Acknowledgment of and addressing the needs of victims, offenders, and the community; assurance of offender (wrong-doer) accountability; collective resolution; reconciliation; atonement; reparation; safety; respect; prevention; communication; openness; and consistency (Alimo-Metcalfe \& Alban-Metcalfe, 2001; Bandura, 1997; Davis, 1980; Errante, 2010; The Society for Safe \& Caring Schools \& Communities, 2006; Thompson, Snyder, Hoffman, Michael, Rasmussen, Billings, et al., 2005; Willower, Eidell \& Hoy, 1967; and Zehr, 2002).

Given the complexity of the Restorative Justice Ideology, each of the above-noted tenets was composed of multiple descriptors. These descriptions were used in the development of the instrument items. Initially 77 items were developed based on these tenets and descriptive statements. Numerous discussions were held amongst the research team during which duplications and ambiguous items were eliminated. Based on this information 33 items were initially retained. The items used were primarily positively worded, with some reverse-worded items used to deter participants from acquiescent response patterns (Nunnally \& Bernstein, 1994); in all instances a 5-point scale was used ranging from 'Strongly Agree' to 'Strongly Disagree'.

This initial phase of Stage 1 effectively met the proposed study goal of developing a construct definition for Restorative Justice (RJ) ideology based on ideas, attitudes and behaviours that are thought to engender restorative justice. It also met the goal of creating an RJ ideology measure based on the definition decided upon in the previous stage of development, 
potentially allowing the measure to be adapted to the different levels of analysis inherent in an organizational culture.

\section{Stage 1, Phase 2}

Data collection. This next phase of the study examined the factor structure of the RJI instrument. A sample of teacher candidates enrolled in a southwestern Ontario university Faculty of Education Pre-Service Program was recruited; population size was approximately 500 teacher candidates from all three instructional divisions (primary/junior, junior/intermediate, and intermediate/senior). The teacher candidates enrolled in these courses were asked to voluntarily participate by completing a pilot version of Restorative Justice Ideology (RJI) Instrument, which included 4 demographic questions and 33 restorative justice ideology items. One hundred and ninety-three pre-service teachers (approximately 39\%) completed the instrument during class time using traditional paper and pencil format. All procedures received home university ethics clearance and were carried out in accordance with the Tri-Council Policy Statement: Ethical Conduct for Research Involving Humans (Canadian Institutes of Health Research, Natural Sciences and Engineering Research Council of Canada, and Social Sciences and Humanities Research Council of Canada, 2010).

Exploratory factor analysis. Exploratory factor analysis (EFA) was conducted with the initial teacher candidate sample to assess the dimensionality of the RJI instrument. This process facilitated insight into the sub-factors (or sub-constructs) that the RJI instrument was measuring. The advantage of this approach was two-fold: it allowed measurement and assessment of subfactors involved in RJI, and it also provided a basis for assessing construct validity.

Focus group interview. Additionally, a focus group interview was conducted to obtain a clearer understanding of School RJ practitioner perceptions concerning whether or not the 
Restorative Justice Ideology (RJI) instrument accurately assessed their understanding and beliefs about restorative justice in schools. Ten participants attended the focus group interview held at the southwestern Ontario university Faculty of Education. The participants included three administrators, six teachers and a child and youth worker (CYW). Participants were provided with an overview of the RJ Pilot Study in 2009.10 and 2010.11, and then were asked to complete the RJI instrument, which was composed of six demographic questions and 33 restorative justice ideology items.

Following the completion of the RJI instrument, and after sharing with participants the construct definition of Restorative Justice Ideology, the participants were asked the following questions for discussion:

- RJ Practices in Schools: What are the characteristics of a teacher, administrator or CYW who is successful in using RJ practices in schools? Is there some sort of belief or attitude that informs their practice?

- RJ Beliefs: Do the questions on the RJI instrument accurately assess what you believe about RJ in schools? What questions are missing? Are there questions that should be revised?

- RJ Ideology: Do you believe that RJI might have an impact on the implementation of restorative justice practices? Do you believe that educators with high scores on the RJI instrument might be more likely to implement restorative justice practices, and those with low scores to be less likely to implement restorative justice practices? Why? How?

- RJ Ideology: Do you believe that Restorative Justice training provided by the School Board might have an impact on the RJI level of school practitioners? Why? How? Recommendations/suggestions? 
The data obtained from the exploratory factor analysis and the focus group interview were analyzed, compared, and discussed by the research team. With regard to the focus group discussions, two important trends emerged. Firstly, it became evident that a disparity existed between the elementary and secondary division, in that those in the elementary division were more cohesive in their use of RJ under the direction of the principal, and through 'entire staff' inservicing. On the other hand, in the secondary division, due to its variety of pedagogical and curricular approaches, the RJ implementation strategy tended to be more diverse. Secondly, primarily due to their roles, administrators, teachers and the child and youth worker interpreted some items in the instrument differently. During the focus group data analysis, it became evident that in its current form the RJI instrument was most suited as a means of identifying teachers' and child and youth workers' RJI.

These discussions led to further refinement of the Restorative Justice Ideology instrument to be used during the final stage of the research study, measurement validation. This resulted in a further reduction in the number of items in the RJI instrument to 22.

Stage 2, Phase 1

Measurement validation. The goal of this stage of the research was to test the usefulness and validity of the RJI instrument (and other important constructs) with teachers. To accomplish this, a superintendent from the local school board sent a request to all of the board's elementary and secondary staff, to voluntarily complete an online survey; this online survey included the following inventories:

- A re-drafted pilot version of the Restorative Justice Ideology Instrument containing 5 demographic questions and 22 Restorative Justice Ideology items - to measure the degree to which individuals identify with a 'restorative justice ideology' 
- Willower, Eidell \& Hoy's (1967) Pupil Control Ideology Form (containing 20 items) - to measure teachers' pupil control ideologies as either humanistic or custodial

- Bandura's Teacher Self-Efficacy Scale (1997) - to measure the kinds of things that create difficulties for teachers in their school activities: efficacy to influence decision making (2 items), instructional self-efficacy (9 items), and disciplinary self-efficacy (3 items)

- Davis' (1980) Interpersonal Reactivity Index (28 items) - to measure thoughts and feelings in a variety of situations with regard to differences in empathy.

The following section provides details regarding participation rates, data analysis, and findings supporting the establishment of the RJI Instrument in its current form.

Data analysis

Exploratory factor analysis. Prior to beginning the EFA process the data were inspected (i.e., all 33 original items) for univariate and multivariate normality. Items that did not have an approximately normal distribution were taken under consideration when eliminating items. A principle-axis exploratory factor analysis was conducted to investigate the factor structure for the RJI based on the sample of 193 student teacher candidates. As a starting point for determining the number of factors the following was relied upon: eigenvalues (greater than 1), scree plots, Minimum Average Partial (MAP) analysis and Parallel analysis.

From these approaches it was determined that there were somewhere between 2 and 4 factors in the RJI instrument. Based on this reference point separate EFAs were run extracting 2, 3 and 4 factors. All analyses were run using a Varimax rotation followed by a Promax rotation allowing the factors to correlate. In this process the loadings, structure coefficients and communality estimates were examined. This information was used in conjunction with the assessment of normality and focus group data when determining the items to be removed for the 
final version of the RJI. Examples of items that were removed include "When a wrongdoing occurs, addressing the long-term implications is most important", and "Students are encouraged to express their feelings in my classroom". Several reasons might have contributed to an item being considered troublesome, including that it might have not been seen as distinct from another item, and that the researchers were not agreed that a high score on the item would necessarily align the respondent with a restorative ideology (see Authors' Note). After removing troublesome items it was determined that the three-factor model best represented these data. A cutoff of .30 was used for all loadings; the three-factor model maximized simple structure and had no cross-loading items. Through examination of the item loadings the three factors were labeled: Restoration, Cooperation and Healing (see Appendix A).

Reliability and correlations. With the factor structure of the RJI established, the reliability and validity of the RJI were examined using a sample of 71 practicing teachers. The reliability of the RJI was assessed using Cronbach's alpha coefficients (Table 2); overall the measure had very good reliability (Kaplan \& Succuzzo, 2005). Bivariate correlations were also computed for the three factors (see Appendix B).

Correlations with related constructs. Bivariate correlations between the three dimensions of RJI (Restoration, Cooperation, and Healing) and three dimensions of empathy (Perspective Taking, Personal Distress and Empathic Concern; using the Interpersonal Reactivity Index) were computed (see Appendix C). Perspective Taking (PT) was positively related to Restoration while the other two RJI factors were not significantly related to PT. Restoration was also positively related to Empathic Concern (EC) whereas the other two RJI factors were not significantly related to EC. Finally, all of the RJI factors were negatively related to the Personal Distress (PD) dimension on the Interpersonal Reactivity Index (Davis, 1980). These results suggest that the 
Restoration factor of the RJI is measuring a similar but different construct than Perspective Taking and Empathic Concern; the direction of these relationships infer that higher levels of PT and EC are associated with higher levels of Restoration. When considering the relationships with Personal Distress, it appears that lower levels of PD are associated with higher levels of Restoration, Cooperation and Healing.

Bivariate correlations were also computed between the dimensions of the RJI and Pupil Control Ideology (see Appendix 3). All of the RJI factors were positively related with Pupil Control Ideology (PCI) implying that more humanistic PCI scores were associated with higher levels of RJI. Furthermore, the relationships provide evidence that the RJI factors are measuring constructs that are similar but different from PCI.

Multiple regression analysis. After assessing the validity and reliability of the RJI it was of interest to determine if aspects of teacher self-efficacy would predict scores on the RJI. This was an important question, as it seems probable that, while not all teachers with a higher level of self-efficacy would necessarily endorse RJI beliefs, it would be difficult for teachers to endorse and act on RJI beliefs without a higher level of self-efficacy. In addition, understanding the way teacher self-efficacy is related to RJI would assist in informing future training and policy development related to restorative justice. The likelihood that teachers who endorsed and acted on RJI beliefs would need a higher level of self-efficacy is based on the following rationale. In order for teachers to demonstrate higher levels of humanistic approaches, which correlate with restorative beliefs and practices (see Appendix C), they would need confidence in their own abilities and knowledge of classroom management (higher self-efficacy). Conversely, teachers who have lower self-efficacy may believe that they are unable to resolve classroom issues within the classroom, and therefore may be more inclined to rely 
on discipline tactics that require external punitive measures (e.g., office visits). Put another way, lower self-efficacy may result in educators relying on 'status quo' discipline tactics because they feel unable (or unequipped) to enact humanistic/restorative practices. More research is needed to explore these findings but the initial results might suggest that selfefficacy may be an important factor in getting teachers to implement humanistic approaches in the classroom, such as restorative justice. Multiple Regression Analysis (MRA) was conducted for each factor of the RJI using dimensions of teacher self-efficacy as the predictors.

Multiple Regression Analysis (MRA) was conducted using global RJI (i.e., a composite of the RJI factors) as the dependent variables and Instructional Self-Efficacy, Disciplinary SelfEfficacy and Decision Making Self-Efficacy as predictors. Prior to any analyses the data were inspected to see that the assumptions of MRA were satisfied. The data were normally distributed without any influential observations; as well, the assumptions of homoscedasticity of errors, linearity and independence of observations were found to be tenable. Since this was an exploratory investigation a stepwise entry method was used in an attempt to generate the best predictive model; an alpha cutoff of .05 was used for all analyses.

With Global RJI entered as the dependent variable; the regression model was significant, $R^{2}=.47, F=29.69, p<.001$ (adjusted $R^{2}=.46$ ). Self -efficacy accounted for $47 \%$ of the variance in Global RJI scores. As anticipated both Instructional Self-Efficacy $(\beta=.39, t=3.80, p<.001$; $\left.s r^{2}=.11\right)$ and Decision Making Self-Efficacy $\left(\beta=.40, t=3.80, p<.001 ; s r^{2}=.12\right)$ were significant predictors of global RJI. These results suggest that increases in Instructional SelfEfficacy and Decision Making Self-Efficacy predict an increase in RJI. 
Summary. The development, assessment and validation of the Restorative Justice Ideology (RJI) scale were completed in three separate phases. First a review of the relevant restorative justice $(\mathrm{RJ})$ literature informed the creation of an operational definition of RJ, as well as a large pool of items (77 items) thought to correspond with this definition. Experts in the RJ field and a panel of practicing teachers were asked to evaluate the items resulting in revisions to the wording of items and a reduced pool of items (22 items).

In the second phase of development an Exploratory Factor Analysis (EFA) was conducted to assess the dimensionality of the RJI scale using a sample of 193 student teacher candidates. From this analysis a 3-factor solution (with 16 items) was found to best represent these data.

In Stage 2, Phase 1, 71 practicing teachers were administered the RJI as well as a package of measures thought to be related to but different from RJI (i.e., empathy and pupil control ideology). In this sample the RJI exhibited a reasonable high level of internal consistency with Cronbach's alpha coefficients ranging from .70 to .89 . Correlations with theoretically related measures demonstrated good convergent and discriminant validity: Pupil Control Ideology .51 to .65; Perspective Taking .20 to .41; Empathic Concern .03 to .27; Personal Distress -.30 to -.34. Taken together these results suggest that the RJI instrument is reliably measuring a unique construct that is similar to but distinct from other previously identified constructs.

After creating and assessing the reliability/validity of the RJI, it was of subsequent interest to determine if aspects of teacher self-efficacy would predict RJI. The rationale for this was based on the idea that teachers with a higher degree of self-efficacy would be more likely to rely on RJ practices and espouse RJ beliefs. Furthermore, because RJ theories typically support creating a democratic, collaborative community environment in classrooms, presumably teacher 
self-efficacy would be an important correlate in this effort. Multiple Regression Analysis (MRA) was conducted for each factor of the RJI using dimensions of teacher self-efficacy as the predictors. Distributional Efficacy and Institutional Efficacy were found to be significant predictors of teacher RJI.

As a result, this study provides a unique measure of RJ that practitioners and researchers alike might use for future applied (e.g., evaluation of training programs) and academic pursuits. Furthermore, the results of this study suggest that future training should incorporate further development of self-efficacy and empathy.

\section{Conclusion \& Recommendations}

The results of this study provide preliminary support regarding the reliability and validity of the Restorative Justice Ideology instrument, although future research should continue to investigate and improve this measure. The RJI instrument, in combination with other related measures (e.g., empathy, emotional intelligence, etc.), could elucidate the effectiveness of RJ training programs and their ability to target both the beliefs and actions of participants. Furthermore, it was found that Empathic Concern, Perspective Taking and Pupil Control Ideology were positively related with RJI. Consequently, it would seem that RJ training programs should consider these aspects when training participants; ideally this would occur in a manner that would enhance both RJI and these ancillary characteristics in tandem. It was also noted that higher levels of Personal Distress were related with lower levels of RJI. This result would suggest that teacher Personal Distress should be minimized prior to having them engage in an RJ training program. Finally, it was found that Instructional Self-Efficacy and Decision Making Self-Efficacy predicted an increase in total RJI and the separate RJI dimensions. In turn, implementation and training of RJ programs would likely benefit by considering ways in which 
teacher Instructional Self-Efficacy and Decision Making Self-Efficacy could be enhanced. This should result in increased RJI amongst teachers, presumably augmenting the usefulness and sustainability of an RJ program within schools.

Therefore, the RJI instrument may be used in several ways, including (a) development of a baseline RJI score for a school board to use with practitioners prior to or during exposure to RJ training, (b) measurement of changes in practitioners' RJI scores following RJ training, and (c) as a foundation for inferences regarding the efficacy of RJ training provided to practitioners by school boards. This empirical data may assist future researchers in exploring the relationship between RJ ideology and classroom RJ practices. In particular, it is important to pay attention to the possible implications of the relationship between restorative justice ideology on the one hand, and desired practice-based outcomes on the other. That is, board interventions may be most impactful when they are first directed towards the individual's underlying beliefs, and then augmented by providing restorative practice training that can be applied in classrooms. Finally, future research should investigate the usefulness of the RJI instrument in predicting teacher behaviors in classrooms and the outcomes of these behavioural strategies.

\section{Limitations}

The current factor structure of the RJI instrument contains one factor (Cooperation) that is entirely comprised of reverse worded items. It is possible that if these items were to be worded in a positive manner, the factor structure of the RJI could change. In addition the RJI instrument was developed using a sample of teacher candidates, consequently future research should examine the fit of this model in a sample of practicing teachers. That is to say, a confirmatory factor analysis using a sample of practicing teachers would dispel much of the limitations in this study and provide further scrutiny of the psychometric properties of the RJI instrument. 
Additionally, since the RJI was only tested in one jurisdiction, the results should not be generalized without discretion onto other populations. Further, since the population tested was pre-service teachers, it is possible that other populations, such as criminal justice professionals working with restorative justice, may have responded differently. Future study that includes such populations is encouraged.

\section{Authors' note}

A compendium of eliminated scale items and a list of the demographic variables that were included in the data analysis are available on request from the corresponding author. 


\section{References}

Alimo-Metcalfe, B. \& Alban-Metcalfe, R.J. (2001, March). The development of a new transformational leadership questionnaire. Journal of Occupational and Organizational Psychology, 74, 1-27.

Amstutz, L. \& Mullet. J. (2005). The little book for restorative discipline for schools. PA: Good Books.

Bandura, A. (1997). Self-Efficacy: The Exercise of Control. New York: Freeman.

Braithwaite, L. (2002). Setting standards for restorative justice. British Journal of Criminology, 42(3), 563-577.

Canadian Institutes of Health Research, Natural Sciences and Engineering Research Council of Canada, and Social Sciences and Humanities Research Council of Canada (2010). TriCouncil policy statement: Ethical conduct for research involving humans. Retrieved from: http://pre.ethics.gc.ca/pdf/eng/tcps2/TCPS_2_FINAL_Web.pdf

Colorosso, B. (2002). The Bully, the Bullied and the Bystander. CA: HarperCollins

Comier, R. (2002). Restorative justice: Promising beginnings. Research Summary, Corrections Research and Development. 7(5). Ottawa, Canada: Department of Public Safety and Emergency Preparedness Canada. Retrieved from http://www.restorativejustice.org/articlesdb/authors/4458

Davis, M. H. (1980). A multidimensional approach to individual differences in empathy. JSAS Catalog of Selected Documents in Psychology, 10, p.85.

Errante, J. M. (2010). An evaluation of two restorative practices on measures of moral disengagement, empathy and forgiveness among incarcerated male juvenile offenders. [Dissertation] TUI University.

Fopiano, J. \& Haynes, N. (2001). School Climate and Social and Emotional Development in the Elementary School Age Child. In J. Cohen, (Ed.). Social and emotional learning and the elementary school-age child. New York, NY: Teachers College Press.

Foss, K. A. (1976). Ideology manifestations in discourse: Toward a methodology for the study of social movements. Essay prepared at Humboldt State University. Retrieved from: http://eric.ed.gov/PDFS/ED149388.pdf

IIRP (2010). International institute for restorative practices factbook. Retrieved from: http://www.iirp.edu/pdf/IIRP-Factbook-2010.pdf 
Institute of Safe Schools in British Columbia. (2005). Safe schools, safe communities. Retrieved from:

http://www.ufv.ca/Assets/BC+Centres+(CRIM)/Safe+Schools/Safe+Schools\$!2c+Safe+ Communities+A+Police+Resource+for+Conducting+Classroom+Presentations/SLO_7_ 12.pdf

Kaplan, R. M., \& Saccuzzo, D. P. (2005). Psychological Testing: Principles, applications, and issues $\left(6^{\text {th }}\right.$ Ed.). Belmont, CA: Wadsworth Thomson Learning.

Karp. D. \& Breslin, B. (2001). Restorative justice in school communities. In Herr, K. (ed) Bringing restorative justice to adolescent substance abuse, Special issue of Youth \& Society 33 (December), 249-272. Thousand Oaks, CA: Sage Publications.

Marshall, T.E. (1999). Restorative Justice: An overview. A Report by the Home Office Research Development and Statistics Directorate. Retrieved from: http://rds.homeoffice.gov.uk/rds/pdfs/occ-resjus.pdf

Nunnally, J. C., \& Bernstein, I. H. (1994) Psychometric theory (2 ${ }^{\text {nd }}$ Ed.). New York: McGraw$\underline{\text { Hill. }}$

Ontario Ministry of Education. (2000). Bill 81, Safe Schools Act. Retrieved from: http://www.ontla.on.ca/bills/bills-files/37_Parliament/Session1/b081ra.pdf

Ontario Ministry of Education, Safe School Action Team. (2006). Safe schools policy and practice: An agenda for action. Retrieved from: http://www.edu.gov.on.ca/eng/ssareview/report0626.pdf

Ontario Ministry of Education. (2007). Bill 212, Education amendment act (progressive discipline and school safety. Retrieved from: http://www.ontla.on.ca/web/bills/bills_detail.do?locale=en\&BillID=1618

Ontario Ministry of Education, Newsroom. (2010). McGuinty government making schools safer, more positive Places to learn (Dombrowsky). Retrieved from:

http://news.ontario.ca/edu/en/2010/02/ontarios-new-school-safety-rules-take-effecttoday.html

Porter, A. J. (2007). Restorative practices in schools: research reveals power of restorative approach, Part II. International Institute for restorative practices: www:iirp.org

Rideout, G., Roland, K., Salinitri, G., \& Frey, M. (2010). Measuring the Impact of Restorative Justice Practices: Outcomes and Contexts. Journal of Educational Administration and Foundations, 21(2), 35-60.

Roche, D. (2003). Accountability in restorative justice. Don Mills, ON: Oxford University Press. 
Stinchcomb, J., Bazemore, G., \& Riestenberg, N. (2006). Beyond zero tolerance: Restoring justice in secondary schools. Youth Violence and Juvenile Justice, 4(2), 123-147.

The Society for Safe and Caring Schools and Communities. (2006, July). A safe and caring approach to restorative practices for schools. Author.

Thompson, L.Y., Snyder, C.R., Hoffman, L., Michael, S.T., Rasmussen, H.N., Billings, L. S., Heinze, L., Neufeld, J.E., Shorey, H.s., Roberts, J.C., \& Roberts, D.E. (2005). Dispositional forgiveness of self, others, and situations. Journal of Personality, 73, 313359.

Watchel, T., \& McCold, P. (2000). Restorative justice in everyday life. In Braithwaite .J. \& Strang, H. (eds). Restorative justice in civil society. New York, NY: Cambridge University Press.

Willower, D., Eidell, T., \& Hoy, W. (1967). The schools and Pupil Control Ideology. University Park, PA: Pennsylvania State University.

Zehr, H. (1990). Changing lenses: A new focus for crime and justice. Scottsdale, PA: Herald Press.

Zehr, H. (2002). The little book of restorative justice. Scottsdale, PA: Good Books 
Table 1

Appendix A

Items and Factor Loadings

\begin{tabular}{lll}
\hline \multicolumn{1}{c}{ Item } & Factor & Loading \\
\hline $\begin{array}{l}\text { 1. Wrong-doing should be addressed without removing the student } \\
\text { from the classroom. }\end{array}$ & Restoration & $(.39)$
\end{tabular}

2. Consequences for wrong-doing should include plans for reintegration into classroom activity.

Restoration (.60)

3. Collective resolution is an appropriate anti-bullying strategy. Restoration (.61)

4. I have a moral duty to help students to get back on track. Restoration (.71)

5. It is my responsibility to develop empathy in students. Restoration (.62)

6. Fear of punishment is a useful strategy in deterring wrong- Cooperation (.35) doings.*

7. When wrong-doing occurs, community members need to express Restoration (.52) their feelings.

8. Repairing hurt requires sustained effort. Restoration (.63)

9. Students who do wrong are deserving of respect. Healing

10. Examples should be made of students who are disruptive.* ${ }^{*} \quad$ Cooperation $\quad(.45)$

11. In righting a wrong only the victim's needs should be Cooperation (.65) addressed.*

12. The victim's voice is more important than the offender's. * Cooperation (.68)

13. Parents should have a voice in the process of righting wrongs. Healing (.46)

14. A wrong-doer who is obnoxious always deserves to be treated Healing with dignity.

15. Wrong-doing should be addressed based solely on the teacher's Cooperation (.35) understanding of the situation.*

16. All members of the class should have a say on how to deal with Healing wrong-doing.

Note. * Reverse coded items 
Appendix B

Table 2

RJI Factor Correlations and Cronbach's Alpha Coefficients

\begin{tabular}{lcccc}
\hline & Restoration & Cooperation & Healing & $\alpha$ \\
\hline Restoration & -- & $.501^{* *}$ & $.679^{* *}$ & .87 \\
Cooperation & -- & -- & $.356^{* *}$ & .85 \\
Healing & -- & -- & -- & .70 \\
\hline
\end{tabular}

Note. $* *$ correlation is significant at the .01 level (2-tailed) 


\section{Appendix C}

Table 3

RJI Factor Correlations and Cronbach's Alpha Coefficients

\begin{tabular}{lcccc}
\hline & $\begin{array}{c}\text { Perspective } \\
\text { Taking }\end{array}$ & $\begin{array}{c}\text { Empathic } \\
\text { Concern }\end{array}$ & $\begin{array}{c}\text { Personal } \\
\text { Distress }\end{array}$ & $\begin{array}{c}\text { Pupil Control } \\
\text { Ideology }\end{array}$ \\
\hline Restoration & $.414^{* *}$ & $.226^{*}$ & $-.332^{* *}$ & $.585^{* *}$ \\
Cooperation & .207 & .210 & $-.298^{*}$ & $.651^{* *}$ \\
Healing & .202 & -.026 & $-.335^{* *}$ & $.507^{* *}$ \\
\hline
\end{tabular}

Notes. $* *$ Correlation is significant at the .01 level (2-tailed)

* Correlation is significant at the .05 level (2-tailed) 


\section{Researchers}

Dr. Karen Roland is a faculty member and the Experiential Learning Specialist for the Faculty of Education, University of Windsor. In this role Karen consults and collaborates with teacher candidates, faculty and school partners as a resource to assist in the development of strategies and programming to address equity and social justice issues in teacher education. Areas of research interest include: social justice education, restorative justice in education, educational equity, teacher education, diversity and policy and administration.

Dr. Glenn Rideout is an Associate Professor at the Faculty of Education, University of Windsor, where he teaches Educational Foundations at the undergraduate level, and courses in Educational Administration, Policy, and Leadership at the Master's and Doctoral level. His research focuses on the changes that occur to pre-service and beginning teachers' approaches to the classroom learning environment (pupil control ideology) and in particular the degree to which their beliefs about education are associated with these changes. Dr. Rideout is currently researching in the area of Restorative Justice at the school level, and is also interested in learning communities, reflective practice, and a variety of topics associated with educational administration, policy, and leadership.

Dr. Geri Salinitri is an Associate Professor at the Faculty of Education, University of Windsor. Mentoring/Social Learning Theory, Cooperative Education and Learning Outcomes, At Risk Youth, Character Education and First Year Student Transition are the areas of expertise for Dr. Salinitri.

Marc P. Frey is a doctoral student in the Social Psychology program at the University of Windsor, specializing in Industrial/Organizational Psychology. Beyond his academic pursuits, Marc consults and collaborates with individuals from a wide range of disciplines, assisting in evaluations and providing methodological support to research projects. Marc's research broadly examines measurement and methodology in organizational settings. 